\title{
Study on the Construction of the Curriculum System of Accounting Major in Higher Vocational College based on "Professional Ability Standard"
}

\author{
Xia Lei \\ Chongqing Business Vocational College, Chongqing, 401331
}

Keywords: Professional Competence, Accounting Profession, Curriculum System

\begin{abstract}
With the development of information technology, the requirement of professional competence of accounting personnel is increasing day by day. This paper analyzes the existing problems in the curriculum system of accounting professional training program in higher vocational colleges in China, and the construction of curriculum system can be effective Solve these problems, and put forward the construction ideas.
\end{abstract}

\section{Introduction}

Talent training program is a baccarat of school personnel training, which mainly solves the professional training to cultivate what kind of talent, how to cultivate, who will train these three core issues, is the school organization teaching activities programmatic document. Among them, the training objectives and personnel training is to answer the question of "cultivating people", curriculum, teaching schedule, the main course description, teaching quality monitoring and protection to answer "how to train people" problem, while the teaching team answered "who To cultivate people "problem. The above content in the personnel training program mutual cause and effect, interrelated, together draw a blueprint for personnel training. Almost every higher vocational college organizes a talent development program every year, and the core content of the talent training program is the curriculum system. This paper analyzes the problems existing in the curriculum of accounting major in higher vocational colleges and puts forward the reform ideas.

\section{The Current Professional Accounting System Curriculum Problems}

Professional curriculum system framework does not reflect the "surname name" characteristics. Today's vocational college has two main components: part of the vocational school was upgraded to higher vocational colleges, and the other part is the new vocational college. By the vocational school upgraded to higher vocational colleges for this part of the school, accounting professional is generally one of the traditional professional, has a long history, with a certain degree of professional precipitation and accumulation, but at the same time will always be bound by the previous curriculum, Wish or do not want to break the tradition, the curriculum has a deep "middle school" brand, the curriculum is almost the reference to undergraduate or other vocational college curriculum, follow the traditional disciplinary curriculum, attention to theoretical knowledge, To a certain extent, deviated from the professional accounting professional training "high-quality technical skills-based professionals," the training objectives, there is no real embodiment of the characteristics of the name of the high title.

The training course has not been implemented. The goal of cultivating accounting talents in higher vocational colleges is to cultivate high-quality technical and technical talents for the society. Therefore, the cultivation of "technical skills" occupies an extremely important position in the cultivation of higher vocational talents. In many colleges and universities, The proportion of the course of about $50 \%$, which would have been in line with the needs of accounting professional training, and only in order to cultivate the accounting staff hands-on ability and practical ability to 
achieve "school and business seamless docking", but in actual execution is often not To achieve, often a "spoon-fed" teaching, pure theory of teaching, the teacher said, students listen, did not really "teaching" one, not really practice teaching into the theory of teaching.

Due to lack of training venues and training facilities are not perfect, training courses can not be implemented, can not achieve the desired results. With the rapid development of information technology, accounting gradually transition from the manual to the electronic account, the transfer of manual billing to the computer billing, lobby declaration to the Internet to declare the transition, etc., the Internet has caused more and more impact on accounting, we have to adapt Social development, to follow the development of the times, we must master more new technology, we need to skillfully operate more accounting software, these new technologies, new software learning needs appropriate training places, teaching is no longer A blackboard, a chalk, a desk can be done. However, due to a variety of reasons, resulting in the majority of the school accounting training venues inadequate training facilities behind, unable to complete part of the training content. For example, "Accounting Integrated Training" This course is a comprehensive training course to achieve a seamless docking between schools and jobs. It aims to develop a comprehensive curriculum for students' accounting, tax calculation, online tax return, financial analysis and financial software Capacity, but due to the limitations of the training site, we can not complete the manual training after the operation of financial software, online tax declaration of these two parts of the content, the purpose of comprehensive training can not be achieved, resulting in the effect of training greatly reduced The

It not pays enough attention to accounting professional ethics education. At present, the curriculum of professional accounting in vocational colleges to professional skills, vocational skills in the first place, directly ignore the accounting professional ethics education. The curriculum is basically based on basic accounting, financial accounting, cost accounting, tax practice, accounting computerization as the core curriculum, supplemented by curriculum practice and simulation training. Although some colleges have set up accounting professional ethics education courses, such as "financial regulations and accounting professional ethics", but only as a qualification examination of accounting practice examinations. Ideological neglect and behavioral neglect, so that a considerable part of the students did not establish a professional ethics of accounting, professional risk awareness, confidentiality and sense of responsibility, in the face of practical work in the moral conflict at a loss.

Vocational training curriculum is not enough. Higher vocational education students should not only have the necessary professional knowledge and skills, but also must have a healthy psychological and adequate career development ability, in the face of new knowledge, new technologies, new skills have enough learning ability, there are Positive spirit, a perfect personality. Our curriculum should not be confined to the profession itself, should be a comprehensive ability to cultivate, is "knowledge + skills + attitude" comprehensive literacy training, it is necessary to take into account the students' career base ability, but also take into account the student's career Development ability, and ultimately enhance the students' comprehensive career ability.

\section{Analysis on Professional Ability of Accounting Major in Higher Vocational College}

The connotation of professional competence. Professional competence is a combination of the ability of people to engage in their profession. For the individual will learn the knowledge, skills and attitudes in specific career activities or contexts of the type of migration and integration formed by the ability to complete a certain professional tasks. Professional ability includes three basic elements: First, in order to be competent for a specific career must have the ability to show the qualifications; Second, after entering the workplace to show the professional quality; Third, after the start of career with career development ability The As the professional ability is a combination of a variety of capabilities, so we can put the professional ability is divided into "professional base ability", "job capacity", "career development ability" three parts. Professional ability is mainly refers to the basic learning ability, writing and language skills, the use of mathematics, spatial judgment, physical perception, color resolution, hand dexterity, hand-eye coordination. In addition, 
any job job requires people to deal with people, so interpersonal skills, teamwork skills, ability to adapt to the environment, and good psychological endurance in the face of setbacks are our indispensable ability in professional activities The Professional job skills mainly refers to the professional ability to engage in a job. Career development ability mainly refers to the sustainable development ability of the profession.

Analysis of professional competence of accounting profession. According to our follow-up survey of graduates found that the initial stage of accounting professional job groups are mainly three categories: First, all types of small and medium-sized enterprise accounting positions; Second, the accounting firm audit assistant positions; Third, the agent accounting company agent accounting positions. Accounting professional development positions are mainly small and medium enterprises to host accounting, finance director, accounting firm project manager, agent accounting company accounting counselor, tax consulting and planning. According to the distribution of accounting professional posts, we analyze the professional competence that the current accounting personnel should have as follows: First, the basic ability of accounting, basic listening, speaking, reading, writing, calculating, skilled computer operation ability, certain foreign language ability , Basic interpersonal communication, teamwork awareness, healthy psychology, correct working attitude. Second, accounting professional job capacity, proficient in accounting, tax returns, financial software operations, to master the basic knowledge of the audit, the use of financial regulations. Third, the professional development capacity, in addition to financial management capabilities, tax planning capacity, accounting, integrated business processing and other professional positions, the good organization and coordination, positive attitude towards life, self-learning and management capacity is also very important.

\section{The Basic Ideas to Build "Vocational Accounting Curriculum System based on The "Vocational Ability}

The basic idea of the curriculum system of higher vocational accounting is based on the "professional competence", which is designed to follow the main line of vocational foundation ability, occupation ability and career development ability.

No matter what kind of career, healthy psychology and good professional ethics are indispensable. The purpose of education is to cultivate people's basic purpose is to cultivate useful people to the country, the people who have a sense of responsibility to the society, and the people who contribute to the enterprise, which requires us to pay attention to the students in the curriculum system design of higher vocational education Mental health education, to help students establish a correct outlook on life and values, so that students have a sound personality, positive and optimistic spirit, enhance students to withstand setbacks and adapt to the environment. Cultivate accounting professionals love and respect their jobs, honest and trustworthy, honest and self-discipline, objective and fair, and strengthen the basic professional ethics. Only in this way can education play its educational role.

Theory is from the practice, practice can not be separated from the theory of guidance, accounting professional has its own characteristics, it is not purely textual emphasis on the theory, nor is the nature of pure science emphasis on practice, but both rationale and rational, coexistence of theory and practice Professional, do not understand the basic principles of not understand the accounting practice can not be carried out, there is no practice of a lot of practice can not understand the theory. Therefore, we must follow the theory of teaching two points: the first can not only talk about empty talk theory, so that a solid body. Such as the classification of vouchers, can not only dry with the text to introduce the type of vouchers, combined with the real voucher style one on the pass; second, the theory must be combined with the vocational qualification test to achieve The Will be the junior accountant title examination, tax account examination of the relevant knowledge points into our daily teaching, theoretical teaching both support and help students successfully pass the examination of vocational qualifications.

Practical teaching occupies an important position throughout the teaching process, students complete these courses, some practical knowledge can be applied directly to the future work. In the 
construction of practical teaching system, the accounting profession insists on the combination of "teaching, teaching and practice teaching", which is a comprehensive and coordinated development of knowledge, skills and quality, and establishes a multi-level practice teaching system which is conducive to cultivating students' practical ability. Course within the class training, curriculum focus on training, comprehensive training three levels. The course is focused on consolidating the students 'basic knowledge and integrating the theoretical knowledge with the practical knowledge. The course is focused on the completion of the core courses at the end of the semester, focusing on the students' ability of accounting basic business and business norms. Training; comprehensive training aims to improve the students on the comprehensive utilization of knowledge, training students to use the basic skills of the comprehensive analysis of the problem to solve the problem, focusing on the comprehensive use of knowledge and skills. In addition to the existing "accounting" and "tax return" two modules of the training content, we will increase the "accounting software use" and "financial analysis" two modules to achieve the comprehensive skills of the real The purpose of training. In addition, all of our current training courses are based on "industrial enterprises" as a case, this is not enough, our students after graduation into the commodity circulation enterprises, construction enterprises, catering enterprises, administrative institutions and so on, and Each type of business has its own characteristics, so accounting should be involved in more integrated training industry.

With the development of the Internet and information technology, machines and software have replaced part of the work of people, and will replace more people's work, we can not still stay in the traditional field of accounting work, only to fill the certificate, calculate the amount of tax , The preparation of the report is far from enough, these will be the most basic accounting professional skills, people will do what? What will accounting do? This is our question worth pondering, accounting has been from the "accounting" quietly to the "management accounting" change, the management of human capacity and comprehensive quality requirements are increasingly high, and thus focus on the future, to adapt to the future development, we It is also imperative to add career development skills courses from now on.

The curriculum system of accounting major in higher vocational education should be based on the cultivation of vocational base ability, take the vocational ability as the core, take the career development ability as the vision, highlight the professional morality, strengthen the vocational skill training, reflect the physical integration, Will be academic education, vocational skills and professional certification of the three closely integrated, the implementation of "double certificate" system to ensure that vocational education professional training objectives to achieve.

\section{Acknowledgements}

Project Name: Chongqing Business Vocational College Talent Training Program Optimization Project: Based on the "professional competence" of the accounting professional training program curriculum system optimization research

No.: swyjjy201501

\section{References}

[1] He Yimin. Discussion on the necessity of introducing original folk songs to university music class-Take Sangzhi folk songs as the example, Music Space Time, 2011,13.

[2] Yang Min. Rethinking the controversy problem of original folk songs, Symphony Journal of Xi'an Conservatory of Music), 2014,01.

[3] He Yimin. Discussion on the necessity of introducing original folk songs to university music class-Take Sangzhi folk songs as the example, Music Space Time, 2014,13.

[4] Ying Na. Discussion on the enlightenment of original folk songs integration into university vocal music teaching, Art Educaiton, 2016 (9) :82- 83. 